\title{
SUPERELASTICITY AND SHAPE MEMORY EFFECT IN COPPER BASE ALLOYS
}

\author{
J. DutKiewicz \\ Institute of Metallurgy and Materials Science of the Polish Academy of Sciences \\ Reymonta 25, 30-059 Kraków, Poland
}

Among the copper base shape memory alloys the most popular are $\mathrm{CuZnAl}$ alloys which however show several features like: tendency to stabilisation, limitation of the effect to low temperatures, lattice defects multiplication after numerous cycling and low decomposition temperatures. This defines the directions of investigations of copper base alloys in order to avoid these negative features limiting their applications. In spite of a large number of investigations of several types of alloys like CuAlNi, CuAlMn, CuAlNiMnTi, CuAlAg, CuGa, CuZn and others, the shape memory properties of NiTi base alloys are considered to be superior and actually are used in a majority of applications in spite of a much higher components cost. In this presentation the investigations of superelastic deformation of mono- and polycrystalline CuAlMn alloys will be discussed. Structure changes during pseudoelastic deformation of CuAlMn single crystals were investigated using in situ optical and high voltage electron microscopy. The effects of ageing on the martensitic transformation temperatures in $\mathrm{CuZnAl}, \mathrm{CuAlMn}$ and $\mathrm{CuZnSn}$ alloys and resulting shift of transformation temperatures are discussed based on the transmission electron microscopy studies. They indicate that changes of ordering within $\beta$ phase are responsible for an increase, while precipitation of bainite or $\gamma$ phase for a decrease in the martensitic transformation temperatures. Ribbons from CuAlNiMn alloy cast using the melt spinning method, crystallizing at a very high rate, show a large drop of $M_{\mathrm{s}}$ temperatures. This drop of $M_{\mathrm{s}}$ depends upon a wheel speed controlling the solidification rate. It is correlated with the decreasing grain size and its value is much larger for ribbons containing titanium due to its grain refinement capabilities. The two-way shape memory effect may appear after the training performed by a repetitive cooling under external stress and heating after unloading. It is demonstrated that in alloys transforming below $150^{\circ} \mathrm{C}$ saturation of the two-way shape memory effect occurs between 50 and 80 training cycles.

PACS numbers: $46.30 . \mathrm{Pa}$

\section{Introduction}

The shape memory effect is observed not only in systems exhibiting thermoelastic transformation, but also in those showing nonthermoelastic martensitic transformation and even the second order transition. However, when it comes to 
practical application of those alloys only a few systems remain attractive, mainly because of economic reasons. In fact the main research effort is directed toward three groups of alloys: TiNi base, copper base, and Fe base alloys. The shape memory effect was described first by Wayman in CuZn alloy [1]. The martensitic transformation temperatures in CuZn system measured by Kurdyumov and Khandros [2] and Pops and Massalski [3] depend upon the zinc content within $\beta$ phase and occur below $-50^{\circ} \mathrm{C}$. It is not very interesting from the point of view of applications, therefore ternary and quaternary additions have been applied and transformation temperatures can be raised above $200^{\circ} \mathrm{C}$ in CuAlNi and CuAlMn alloys $[4,5]$. The important feature however is the stability of martensitic transformation temperatures which determines the application of alloys. Two factors should be taken into account: (i) a shift of temperatures due to ageing at elevating temperatures where the transformation takes place [6] and (ii) stabilization of martensite, i.e. the shift of the first transformation cycle temperature toward higher temperatures [7]. Depending on the alloy composition two types of precipitates can be observed: bainitic copper rich, the formation of which causes a drop of transformation temperatures and $\gamma$ zinc or aluminium rich precipitates, the appearance of which shifts transformation temperatures downwards [8].

Diffusional processes during low temperature ageing are responsible for the stabilization of martensite. The upward shift of transformation temperatures increases with the extent of diffusion. Martensite stabilization is more frequently observed in material that transforms to martensite above room temperature as diffusion is faster at above ambient temperatures. The changes in martensite causing stabilization are removed during its retransformation and the material returns to its normal transformation characteristics $[7,9]$.

In order to understand the mechanism of pseudoelastic deformation in $\beta$ phase copper base alloys, in situ optical microstructure observations during tensile deformation were reported on CuAlNi [10], CuZnSn [11], CuAlZn [12] and CuAlMn [13] alloys. They showed different results regarding the nucleation and growth of various kinds of stress induced martensites, their orientation with respect to the tensile axis [10] and the interaction with grain boundaries during particular deformation stages. The formation of martensitic plates in single crystals occurs often in the form of parallel plates which grow during deformation, but interfaces do not disappear completely [11]. This is surprising since an increase in the number of interfaces increases the internal energy of the system [14], and one would expect a coalescence of the individual plates. On the other hand, at the resolution of the optical microscope one cannot distinguish narrow plates of different orientations from interfaces within one plate. From a change of martensite morphology one can draw conclusions on the structure of martensite, but it has to be confirmed by X-ray diffraction. Simultaneous X-ray diffraction studies during pseudoelastic deformation of $\mathrm{CuAlFe}$ [14] alloys allowed to identify the following sequence of martensitic phases formation with increasing strain: $\gamma_{1}^{\prime} \rightarrow \beta_{1}^{\prime} \rightarrow \alpha_{1}^{\prime}$. Additionally the crystallographic relationships were found between the parent and the martensitic phases. In situ deformation during transmission electron microscope observation of CuAlZn and CuAlFe alloys [15] yielded additional information regarding the defect and interface structure as well as the crystal structure 
and orientation of particular plates forming at successive deformation stages. This method was therefore chosen to study a development of martensitic structures in CuAlMn alloys, which has been shown to consist of $\gamma_{1}^{\prime}, \beta_{1}^{\prime}$, and $\alpha_{1}^{\prime}$ phases [14].

Another interesting feature which is being developed in shape memory applications is a rapid solidification technique [16-20]. Copper base shape memory alloys cast using the melt spinning method has been intensively studied since they possess a finer grain size [16-20] and superior mechanical properties $[18,19]$ when compared to the bulk. Another characteristic feature of rapidly quenched ribbons is depression of martensitic transformation temperatures which was connected with a higher cooling rate [16] or a much finer grain size [17, 19]. However, in CANTIM alloys containing $1 \mathrm{wt} . \% \mathrm{Ti}$, the change of transformation temperatures is connected also with an increased solute content within $\beta$ phase and decreased degree of ordering as mentioned also in CuAlZn and CuAlNi alloys [18]. The latter feature was not confirmed in other works, where an increased degree of ordering in rapidly quenched ribbons was reported [20]. Due to complexity of transformations the role of various factors has not been well understood yet. Therefore, further results of the effect of grain size and titanium content on the martensitic transformation in rapidly quenched ribbons are given in this presentation.

\section{Superelastic deformation of mono- and polycrystals}

Figure 1 shows stress/strain curves of a single crystal of $\mathrm{Cu} 10.2 \% \mathrm{Al}$ and $9.5 \% \mathrm{Mn}$ (all compositions in wt.\%) of the [001] orientation deformed at various temperatures. Their change with temperature is similar to that reported for tensile tests in $\langle 100\rangle$ direction of CuAlNi [11,12] and CuAlFe alloys [14]. The stress/strain curve below $M_{\mathrm{f}}\left(-17^{\circ} \mathrm{C}\right)$, where a thermal martensite is deformed, is characterised

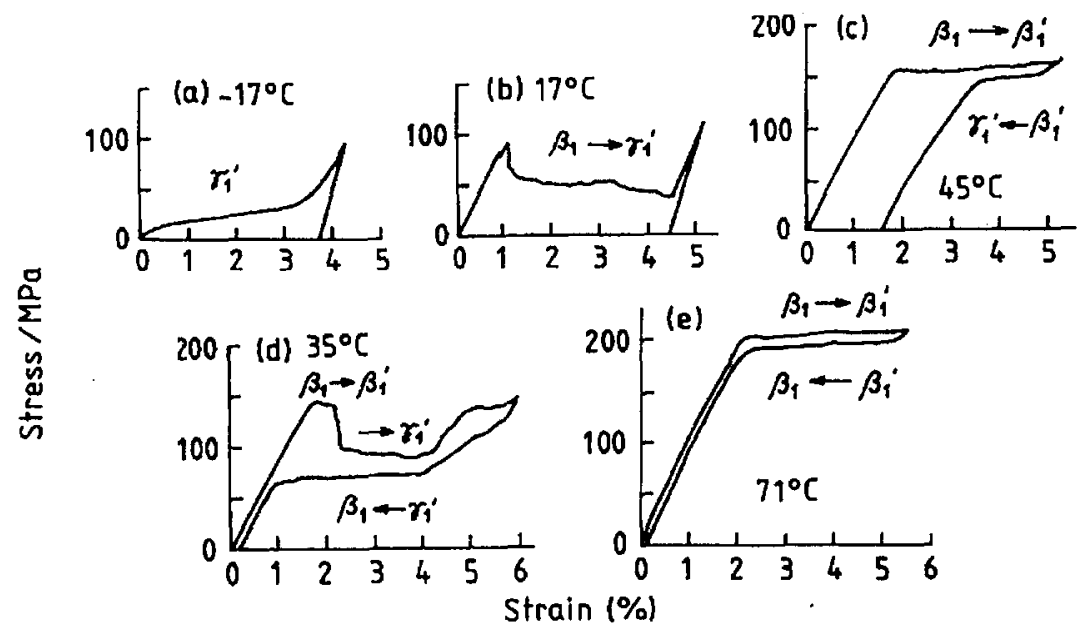

Fig. 1. Stress/strain curves of a single crystal of $\mathrm{Cu} 10.2 \% \mathrm{Al}$ and $9.5 \% \mathrm{Mn}$ of the [001] orientation deformed at various temperatures. 
by a smooth curve, since during the deformation, only a movement of martensitic interfaces occurs. The residual strain left after unloading was completely recovered by heating the specimen above $A_{\mathrm{f}}$. The stress/strain curve obtained very close to the $M_{\mathrm{s}}$ temperature (at $17^{\circ} \mathrm{C}$ ) shows a large serration due to formation of stress induced $\gamma_{1}^{\prime}(2 \mathrm{H})$ martensite. The stress/strain curves above $A_{\mathrm{f}}$ show a pseudoelastic behaviour, however the complete superelastic curve cannot be obtained between $M_{\mathrm{s}}$ and $35^{\circ} \mathrm{C}$. In this temperature range the martensite induced during tensile deformation cannot completely return to the parent phase during unloading. The stress required for a shift of martensitic interfaces is lower than that to form $\gamma_{1}^{\prime}$ martensite, while a highest stress is necessary to form $\beta_{1}^{\prime}$ martensite [13].

Figure 2a shows a load/elongation curve taken from a single crystal in [001] $\beta_{1}$ orientation tested in tension in a $[100] \beta_{1}$ direction. A series of micrographs was
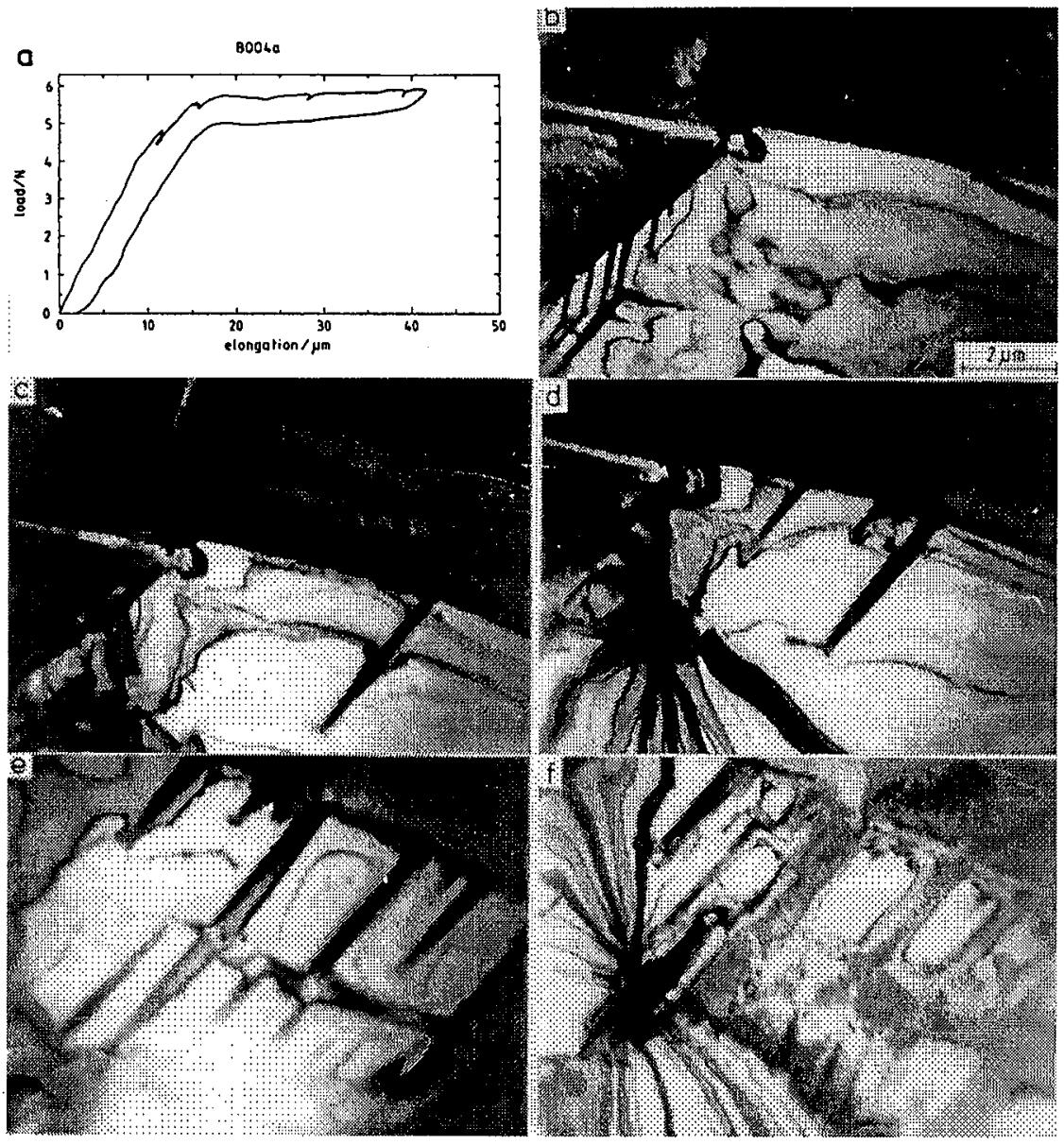

Fig. 2. (a) Load/elongation curve recorded during in situ HVEM deformation in $\langle 100\rangle \beta_{1}$ direction. (b-f) Set of transmission electron micrographs recorded during in situ tensile deformation. 
reproduced from video recordings taken during in situ high voltage electron microscopy (HVEM) deformation. The first micrograph of the series was taken just before attaining the yield stress (as marked in Fig. 2a), but already a large plate existed in the crystal (Fig. 2b). The following micrograph (2c) shows the nucleation of a small single needle at the existing one. It grows parallel to the tensile axis. The following micrographs show the formation of other needles near the first one $(2 \mathrm{~d}-\mathrm{e})$ and the nucleation of needles in transverse direction (2e). At a final stage small plates join into the single large plate. This observation is consistent with in situ optical microscope observations, where the nucleation of parallel plates was shown.

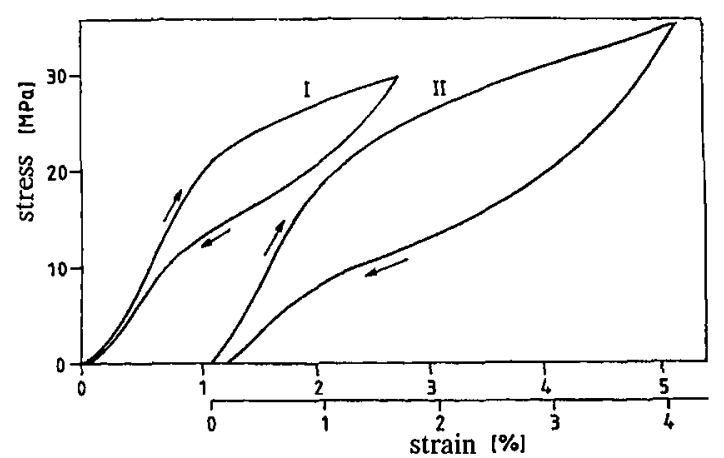

Fig. 3. Stress strain curve of superelastic polycrystalline CuAlMn alloy transforming just below room temperature.

Figure 3 shows stress strain curves of polycrystalline CuAlMn alloy transforming below room temperature. One can see that tensile curves are different than those of monocrystals. The stress increase is much more steep and there is no stress plateau as in the case of monocrystals. After unloading a small permanent deformation exists, most probably due to the deformation of regions near grain boundaries. Nevertheless several deformation cycles up to $2-3 \%$ elongation can be performed.

\section{The effect of ageing on the martensitic transformation}

Figure 4 shows the changes of $M_{s}$ temperatures of CuZnSn alloys after ageing at $200^{\circ} \mathrm{C}$. One can see that in all alloys containing: $\mathrm{A}-\mathrm{Cu} 40.4 \% \mathrm{Zn}, \mathrm{B}-$ Cu $33 \%$ Zn $5.8 \%$ Sn, C - Cu 25\% Zn $10.5 \%$ Sn, D - 21.8\% Zn $10.8 \%$ Sn transformation temperatures increase in the first stage of ageing due to an increase in $\mathrm{B} 2$ and $\mathrm{DO}_{3}$ ordering as illustrated by TEM micrographs insets in Fig. 4. Then a decrease in $M_{\mathrm{s}}$ temperatures is observed due to the precipitation process either of bainite (as illustrated in the inset) or of $\gamma$ phase. Depending on the composition, alloys show different resistance to ageing which depends on the composition of the alloy determining the kind of precipitates and kinetics of the diffusion processes.

The differential scanning calorimetry (DSC) traces taken from Cu $10 \% \mathrm{Al}$ $9 \% \mathrm{Mn}$ alloy after various periods of ageing time (Fig. 5) show changes of transformation heat during heating and cooling. The peaks show a shift of characteristic 


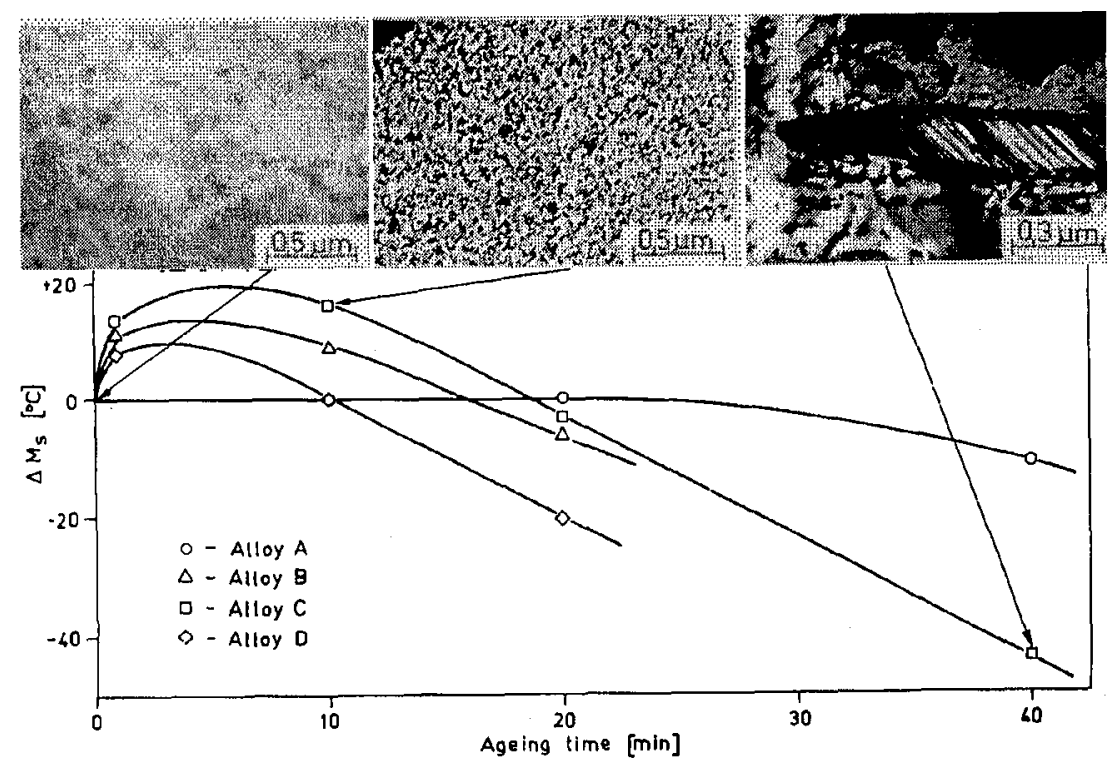

Fig. 4. The changes of $M_{\mathrm{s}}$ temperatures of $\mathrm{CuZnSn}$ alloys after ageing at $200^{\circ} \mathrm{C}$.
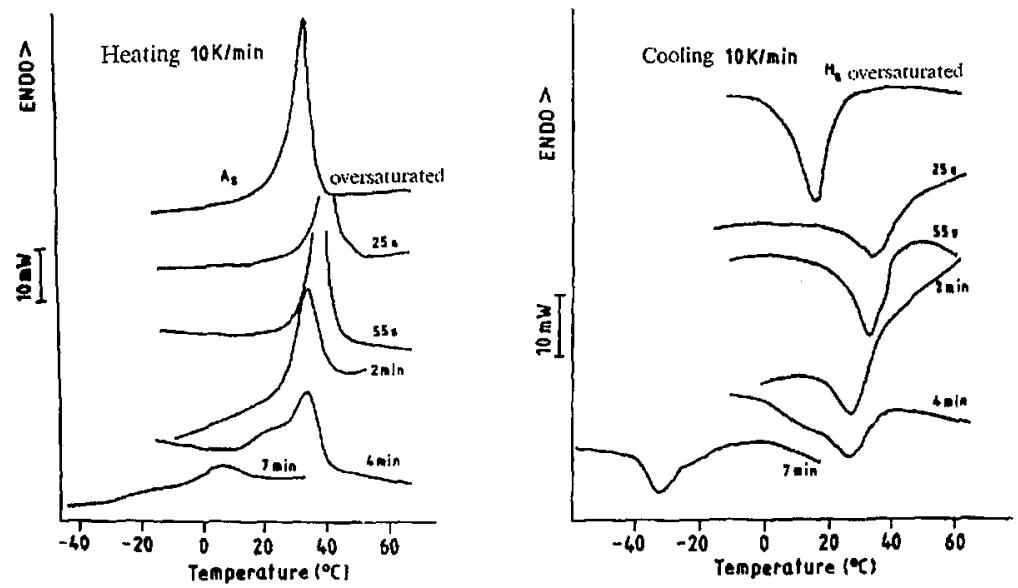

Fig. 5. DSC heating/cooling curves of alloy 5 showing changes of characteristic transformation temperatures and volume transforming after ageing at $300^{\circ} \mathrm{C}$.

temperatures with time of ageing and are gradually becoming smaller due to limitation of a volume of the material transformed. They are becoming also more diffused due to a gradient of composition near precipitates and stresses involved.

\section{Stabilisation of the martensite}

Stabilisation as already noted, results from a thermally activated process. Its extent can be affected by the presence of vacancies introduced into the martensite 
prior to ageing. Copper base alloys are usually quenched to retain the $\beta$ phase for further transformation to martensite. The mode of the quench and any further treatments will determine the concentration of vacancies left in the martensite to accelerate diffusion. Ageing of directly quenched (DQ) alloys leads to a most rapid and serious stabilisation. The retransformation of martensite to $\beta$ may even be lost in this case, if the alloy transforms nominally at as high temperature as $100^{\circ} \mathrm{C}$. Step quenched water bath (SQWB) samples provide the most stable martensite transformation and shape memory behaviour with time after the treatment. This should obviously be related with the decreasing of the vacancy density after these treatments.

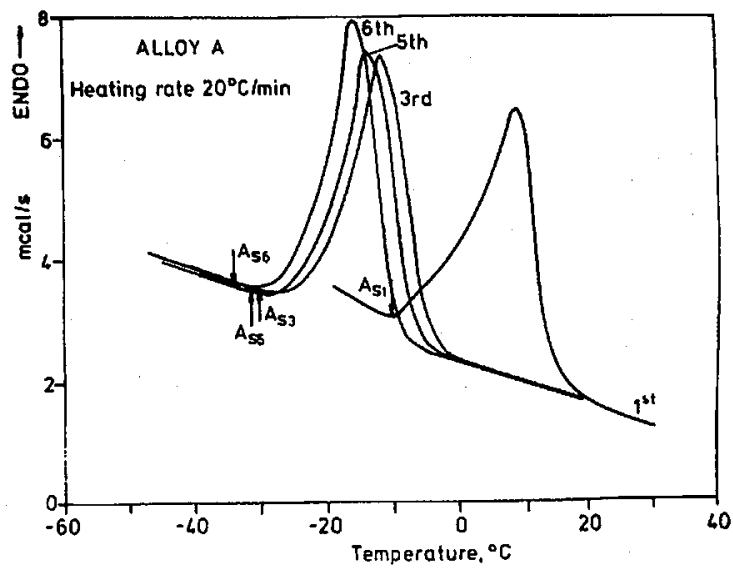

Fig. 6. DSC heating curves of the followig first, third, 5th, and 6th DSC heating cycles taken from the $\mathrm{Cu} 30.7 \% \mathrm{Si} 4.3 \% \mathrm{Si}$ alloy quenched from $850^{\circ} \mathrm{C}$ to water and then to alcohol at $-60^{\circ} \mathrm{C}$.

Figure 6 shows the following first, third, 5th and 6th DSC heating cycles taken from the $\mathrm{Cu} 30.7 \% \mathrm{Si} 4.3 \% \mathrm{Si}$ alloy quenched from $850^{\circ} \mathrm{C}$ to water and then to alcohol at $-60^{\circ} \mathrm{C}$. The stepwise return of the reverse transformation temperatures is clearly evident. This effect is not the effect of cycling, but should be attributed to the changes in the atomic arrangement related to the return to martensite to its pre-stabilisation state. The structure and the microstructure of the stabilised martensite was compared to that of the unstabilised martensite. A quantitative comparison here, however should be done consciously, since the martensite was thinned at subambient temperatures, and the martensite was observed in in situ cooled thin samples. From the diffraction patterns presented in Fig. 7 one can see that the monoclinic angle of the $9 \mathrm{R}$ stabilised martensite is close to $90^{\circ}$ (as estimated after measuring the angle between 009 and 300 reflections), while that of unstabilised martensite is equal to $88^{\circ}$. This observation may indicate that martensite changes slightly its structure during heating, which may be connected with the migration of vacancies. Another feature of the stabilised martensite which seems to be important is the stacking fault structure. It is related to nonbasal stacking faults [21] on (114) planes and to basal stacking faults. Figure 8 shows 

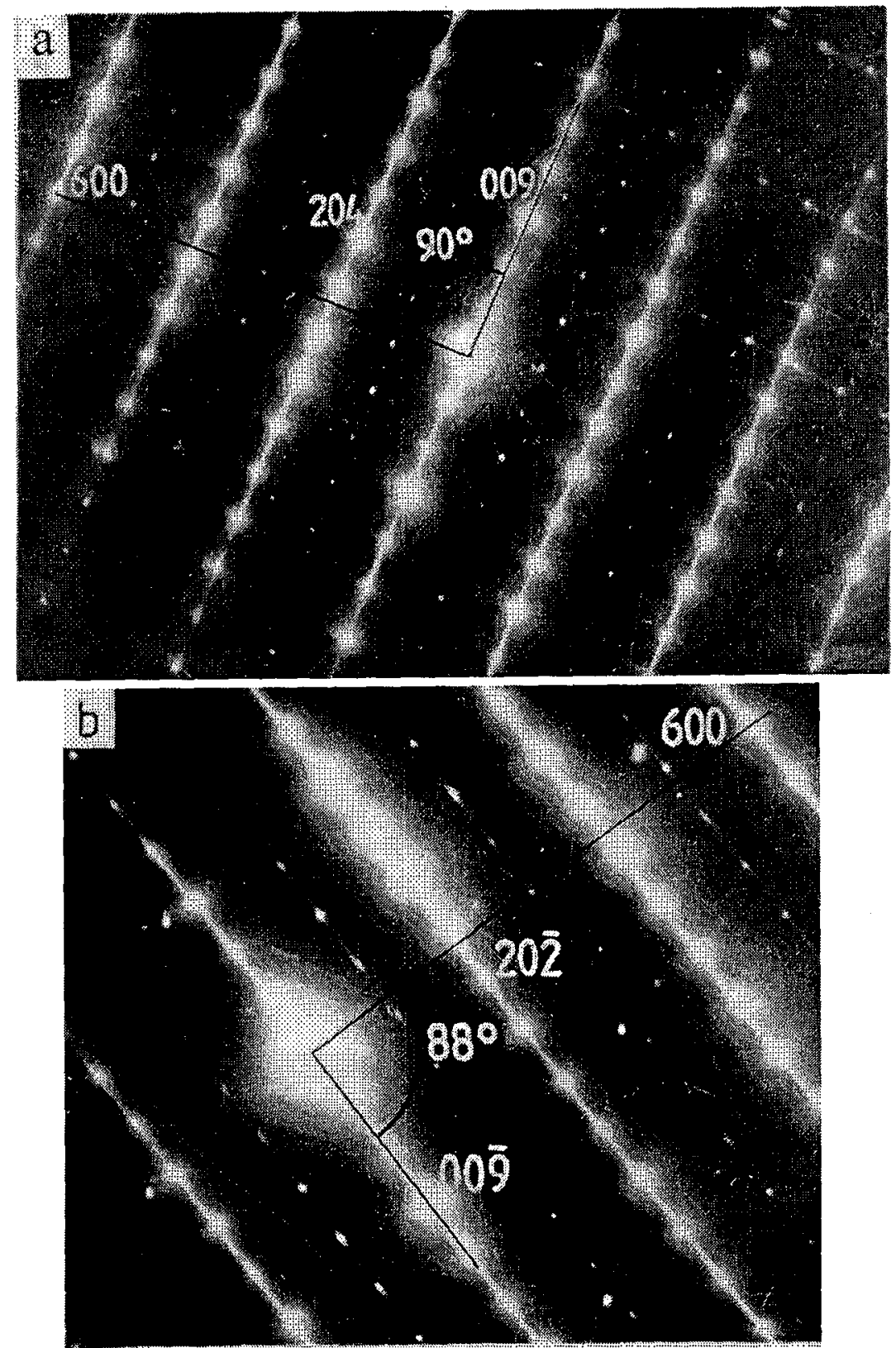

Fig. 7. Selected area diffraction patterns taken from stabilized (a) and unstabilized in situ cooled martensites at [010] zone axis orientation showing different angles between 009 and 600 reflections.

the lattice image of as-quenched martensite in CuZnSi alloy, where a mixture of $3 R$ and $9 R$ structures showing different periodicities can be seen. The $3 R$ structure corresponds to the $0.21 \mathrm{~nm}$ periodicity, while that of $9 \mathrm{R}$ is three times larger. The 


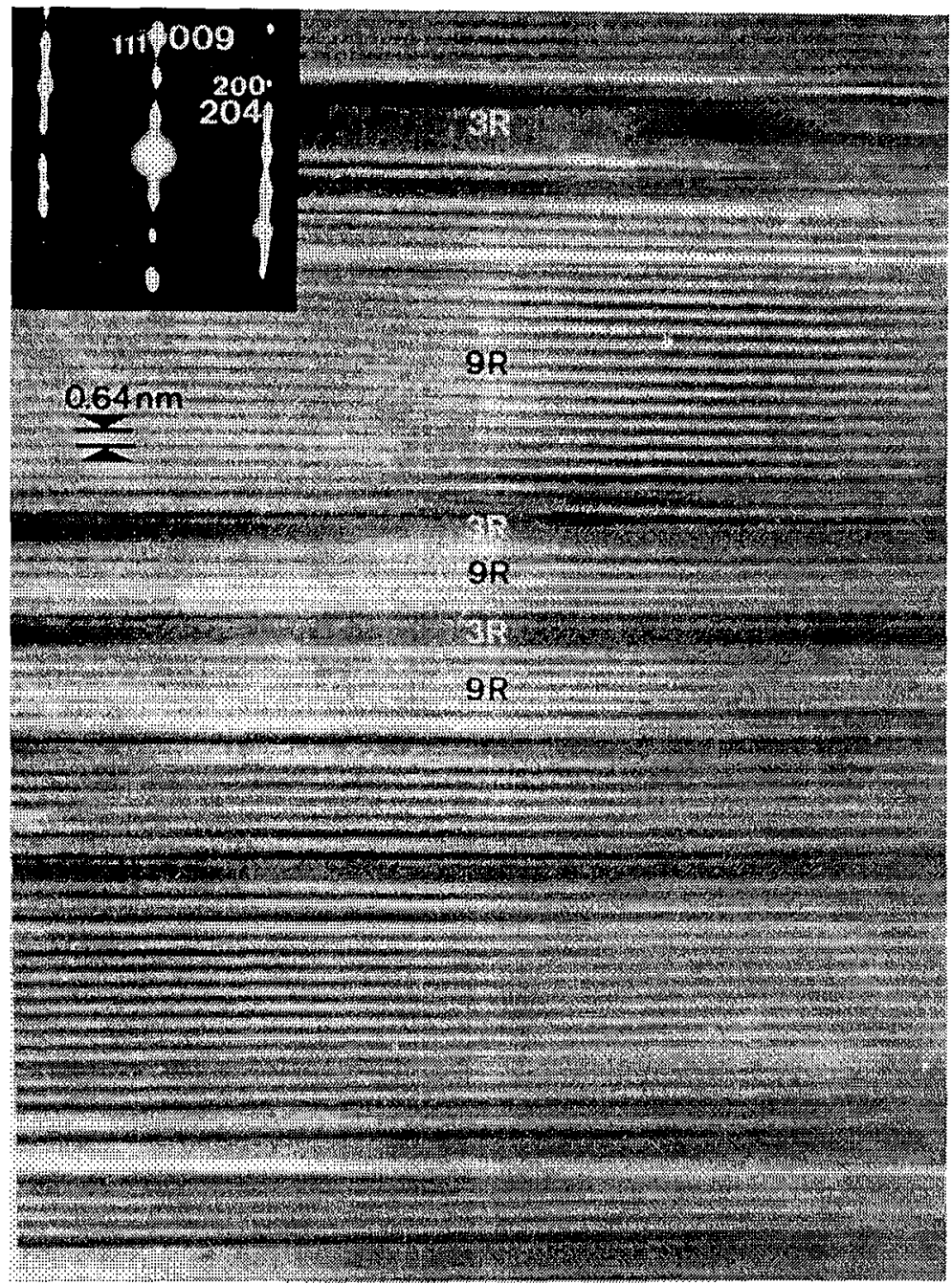

Fig. 8. The lattice image of as-quenched martensite in $\mathrm{CuZnSi}$ alloy, where two types of $3 R$ and $9 R$ martensite layers of different periodicities can be seen.

narrow plates of $3 \mathrm{R}$ structure cause streaks in the diffraction pattern presented as an inset in the micrograph. The $3 \mathrm{R}$ lamellae were also observed by Stobbs in as-quenched $\mathrm{CuZnAl}$ alloys [22], however the effect of stacking faults is not considered as important for the stabilisation $[7,9,21]$ since it shows many differences from one plate to another.

\section{Two-way shape memory effect (TWSME)}

Figure 9 shows the dilatometric curves obtained for alloy $10 \mathrm{a}(\mathrm{Cu} 10.4 \% \mathrm{Al}$ $3 \% \mathrm{Mn}$ ) quenched to $200^{\circ} \mathrm{C}$ after different numbers of training cycles (applied tensile stress of $66 \mathrm{MPa}$ ). One can see that the amount of TWSME (defined by the spontaneous elongation during cooling) increases considerably with the training 


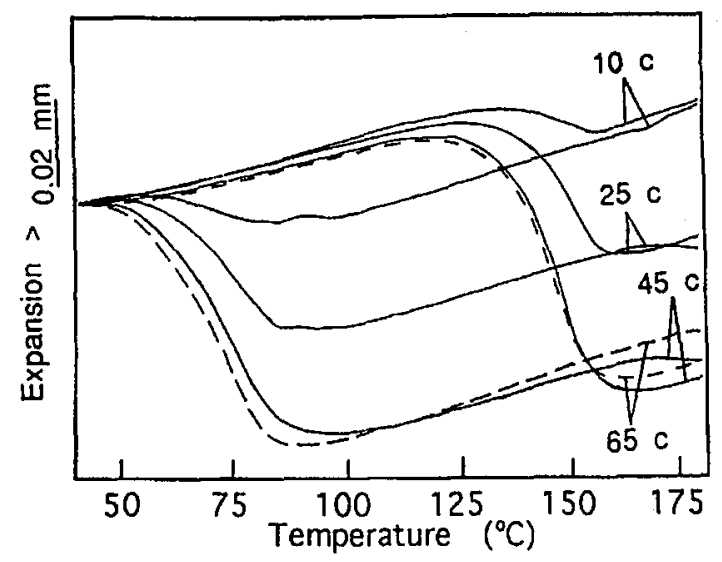

Fig. 9. Dilatometric curves for alloy $10 \mathrm{a}$ quenched to $200^{\circ} \mathrm{C}$ after the indicated number of training cycles (training stress of $66 \mathrm{MPa}$ ).

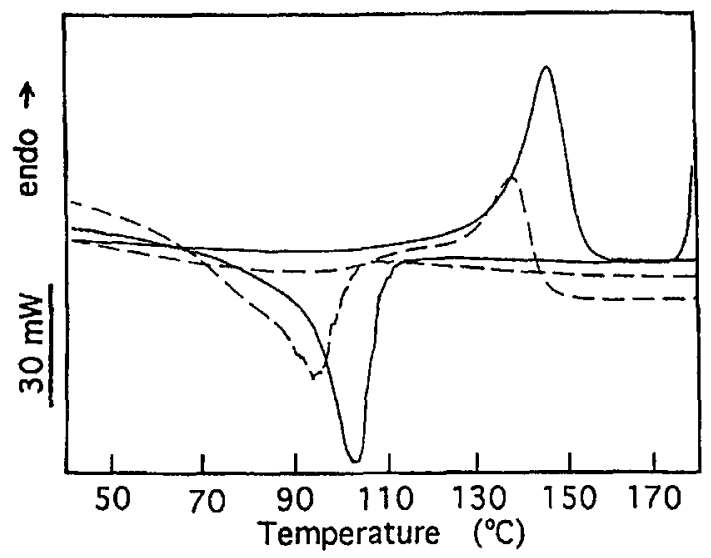

Fig. 10. DSC curves recorded over the martensitic transformation range in alloy 10a as-quenched to $200^{\circ} \mathrm{C}$ (full line) and after 85 training cycles under $66 \mathrm{MPa}$ (dashed line).

until 45 cycles. The measurements after 65 training cycles show already a small deterioration of the effect connected with a slight hysteresis widening. After a higher number of cycles this effect becomes more clear and also the curves slightly shift to lower temperatures. The evolution of the extent of TWSME with the number of training cycles is different depending on the transformation temperature. For CuAlMn alloy transforming at subzero temperatures, TWSME saturation occurs after about 50 cycles, while for alloys transforming close to $200^{\circ} \mathrm{C}$, the TWSME saturates after $20-40$ cycles. These results indicate the existence of some thermal effects affecting saturation values and training efficiency [23].

Calorimetric examination of trained alloys showed that the heat of forward and reverse martensitic transformations was considerably lower (about $30 \%$ ) than in the as-quenched samples, similarly as reported for CuZnAl alloys [24]. The broadening of peaks after training and their shift towards lower temperatures 
(a)

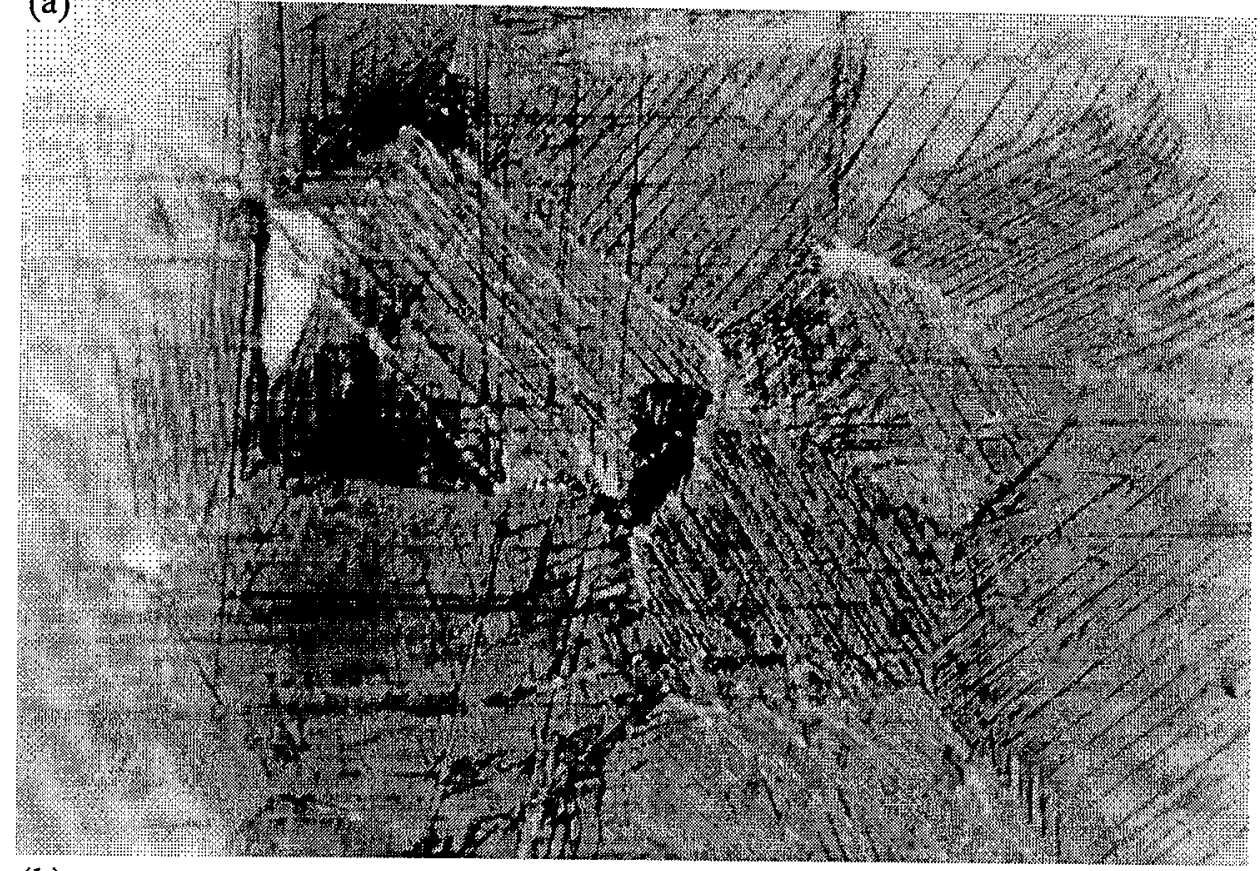

(b)

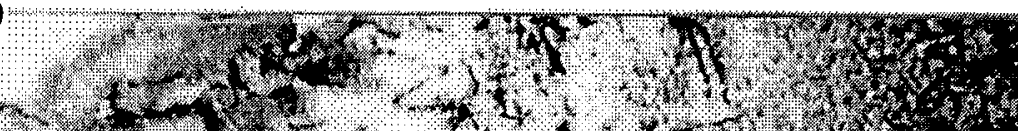

$\mathrm{m}$
$\mathrm{m}$

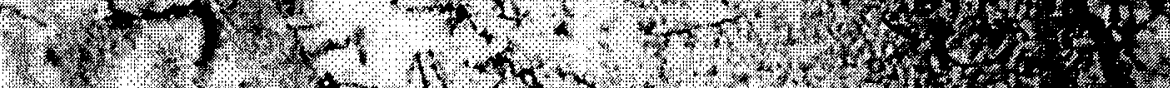

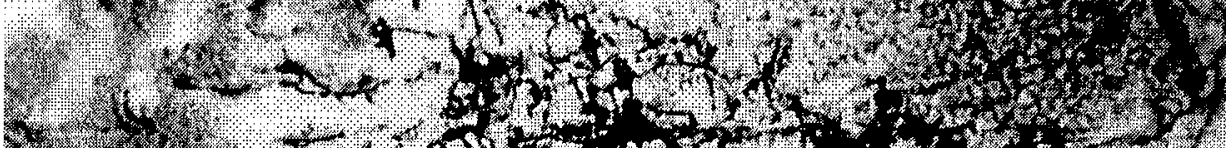
(2)

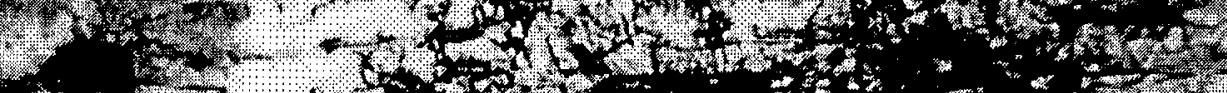
(10)

710.

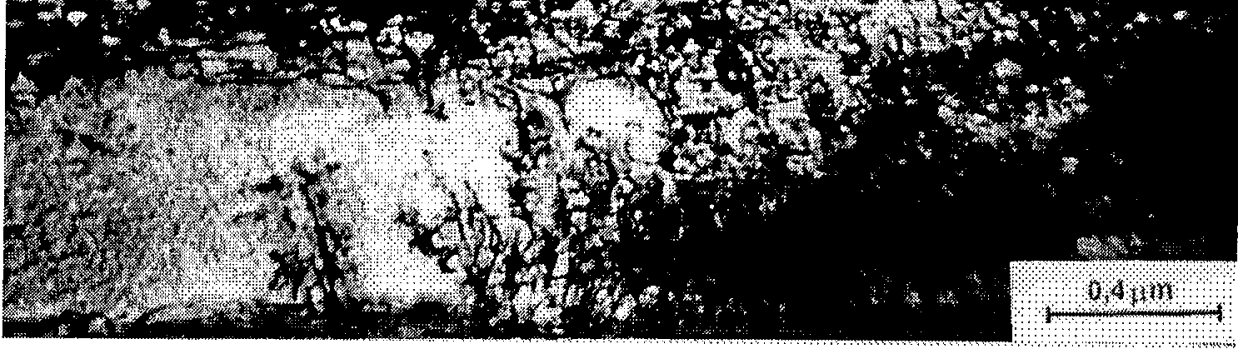

Fig. 11. Optical micrographs of alloy 5c after 80 training cycles at $66 \mathrm{MPa}$ (a) and transmission electron micrograph after this treatment (b). 
is characteristic of all alloys examined, as it can be seen in Fig. 10, where the calorimetric curves of as-quenched and trained alloy $10 \mathrm{a}$ are presented. The shift towards lower temperatures can be explained by formation of differently oriented variants (as suggested in Ref. [24]) and/or by the simultaneous formation of $\gamma_{1}^{\prime}$ and $\beta_{1}^{\prime}$ martensites, as observed by TEM in the present alloys indeed.

The lower values of transformation heat after training are due to the presence of residual (and stabilised) martensite. Contrary to the observations of Stalmans et al. [25], overheating of the trained samples did not cause disappearance of the residual martensite in the investigated alloys, as can be observed in Fig. 11a, where the amount of martensite in the trained sample of alloy $5 \mathrm{c}$ before and after a $10 \mathrm{~s}$ flash heating at $250^{\circ} \mathrm{C}$ is very similar. In the other alloys the amount of residual martensite could not be estimated using optical microscopy at room temperature since they were fully in martensitic state. They were heated in the calorimeter up to $400^{\circ} \mathrm{C}$, but no additional peaks above the reverse transformation were found. This indicates that in CuAlMn alloys the martensite stabilises easily either thermally or upon deformation. The latter was already observed earlier in these alloys [26], where $10 \%$ of deformation by rolling prevented retransformation of martensite.

Figure $11 \mathrm{~b}$ shows such a band in alloy $5 \mathrm{c}$ subjected to 80 training cycles. Most of dislocation bands are parallel to $\langle 110\rangle_{\beta}$ direction. The density of dislocations within a centre of a band is so high that single dislocations rarely can be distinguished, but no small martensite plates within bands, as observed in Ref. [27] after training, were found in the present case. The plates were often attached to bands but not within them.

A different dislocation structure was observed in alloys transforming at higher temperatures, where a fairly uniform distribution of dislocations was usually observed. The thermally activated dislocation motion is most probably one of the main reasons that no dislocation bands are formed in alloys transforming at higher temperatures. Consequently, dislocation bands cannot act as nucleation sites of preferred variants and the training is less efficient.

\section{The effect of rapid solidification on the martensitic transformation}

In CuAlMnNiTi shape memory alloys with increasing Ti content up to $1 \%$, grains are both smaller and of elongated shapes. It is due to the presence of Ti rich precipitates preventing grain growth during annealing. The sample with a higher manganese content is not as efficiently modified by titanium addition as the others. Figure 12 shows a set of DSC cooling curves for bulk and melt spun ribbons of alloys $90(\mathrm{Cu} 11.85 \mathrm{Al} 3.2 \% \mathrm{Ni} 3.0 \% \mathrm{Mn}$ ) and 94 (Cu 11.4\% Al 2.5\% Ni 5.0\% Mn 0.4\% Ti). In both alloys martensitic transformation peaks are shifted toward the lower temperatures and they are also becoming smaller and more diffused over the temperature range with increasing wheel speed, i.e. solidification rate. Both alloys cast. with a higher wheel rotation speed show peak splitting, which is most probably due to the formation of two variants of martensite, i.e. $18 \mathrm{R}$ and $2 \mathrm{H}$ as previously observed for CuAlMn [28] and CuAlMnNi alloys [29]. This feature is apparently more pronounced in alloys cast at a higher wheel speed, i.e. with a smaller grain size, however in alloy 94 it may also result from the stress accommodation due to small precipitates formation at a higher cooling rate. They are consumed by 

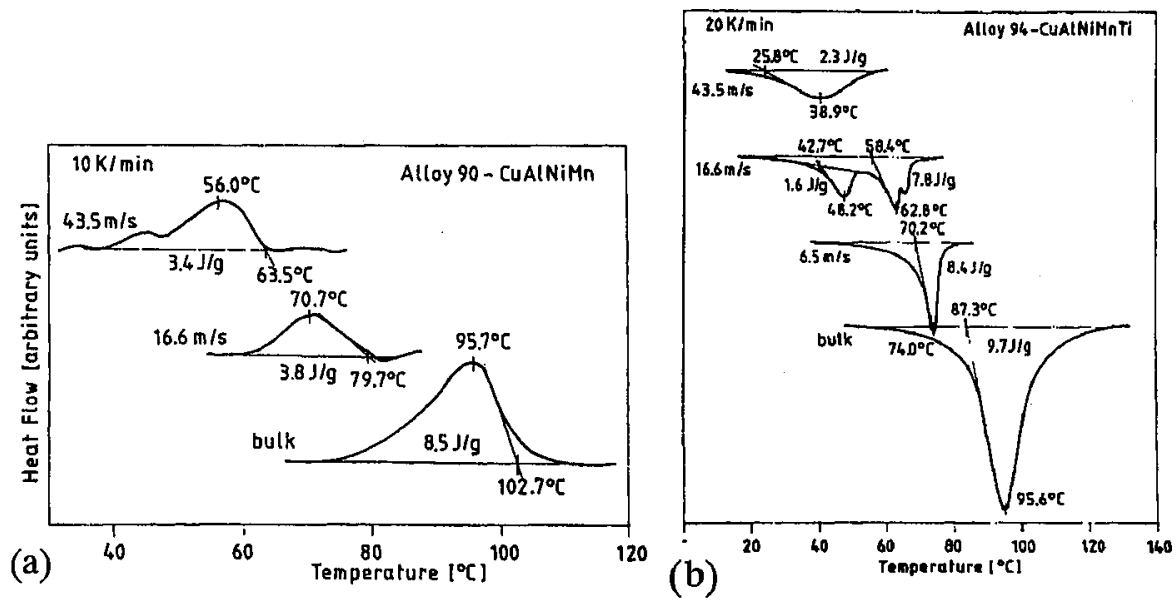

Fig. 12. DSC cooling curves for alloys 90 (a) and 94 (b) melt spun at various wheel speeds.

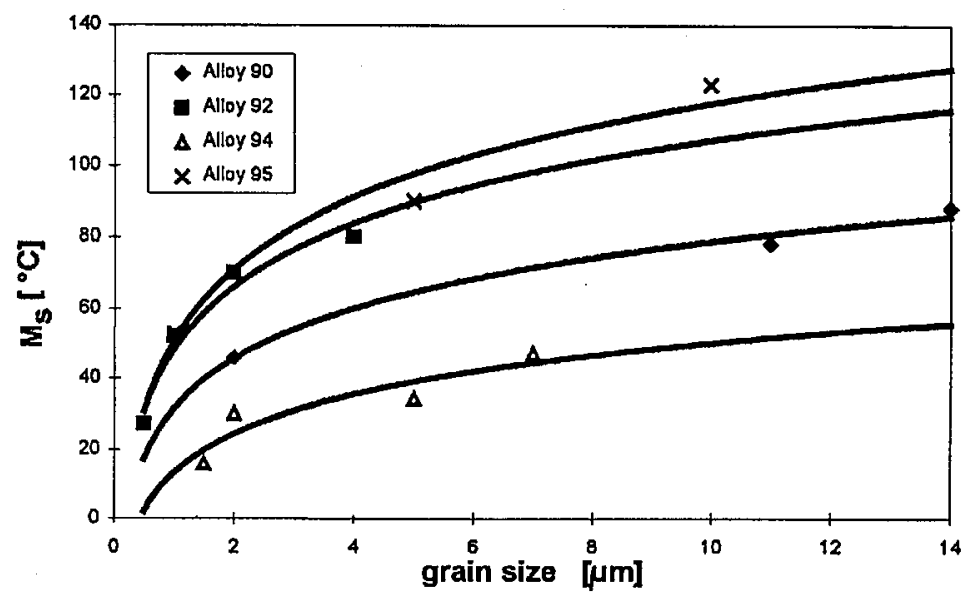

Fig. 13. Relationship of $M_{\mathrm{s}}$ vs. grain size $d$.

the martensite as observed in aged CuAlMn alloys with $\gamma$ precipitates [28]. Precipitates cause also broadening of transformation hysteresis [28] as observed for higher cooling rates. Figure 13 shows the diagram illustrating $M_{\mathrm{s}}$ vs. grain size relationship for the investigated alloys melt spun at different cooling rates. One can see that with decreasing grain size from 14 to about $4 \mu \mathrm{m}, M_{\mathrm{s}}$ temperature is only slightly decreasing, but in the finer grain size range, the drop of transformation temperatures is more rapid. Since a much smaller grain size can be attained. for ribbons with titanium content they show a more steep beginning of the curve. This effect is better seen in Fig. 14, where the same data are presented in the form $\Delta M_{\mathrm{s}}=f(d)^{-1 / 2}$ (where $\Delta M_{\mathrm{s}}$ is equal to the difference between the $M_{\mathrm{s}}$ of the ribbon and of the bulk alloy and $d$ is the grain size. The relationship can be fitted as a straight line for all alloys investigated. It suggests that the effect of supersat- 


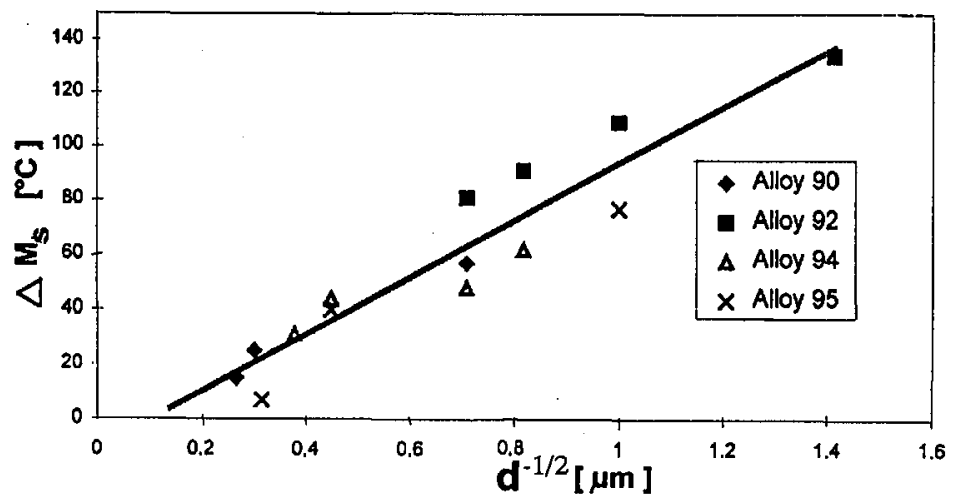

Fig. 14. Relationship of $\Delta M_{\mathrm{s}}$ vs. $d^{-1 / 2}$.
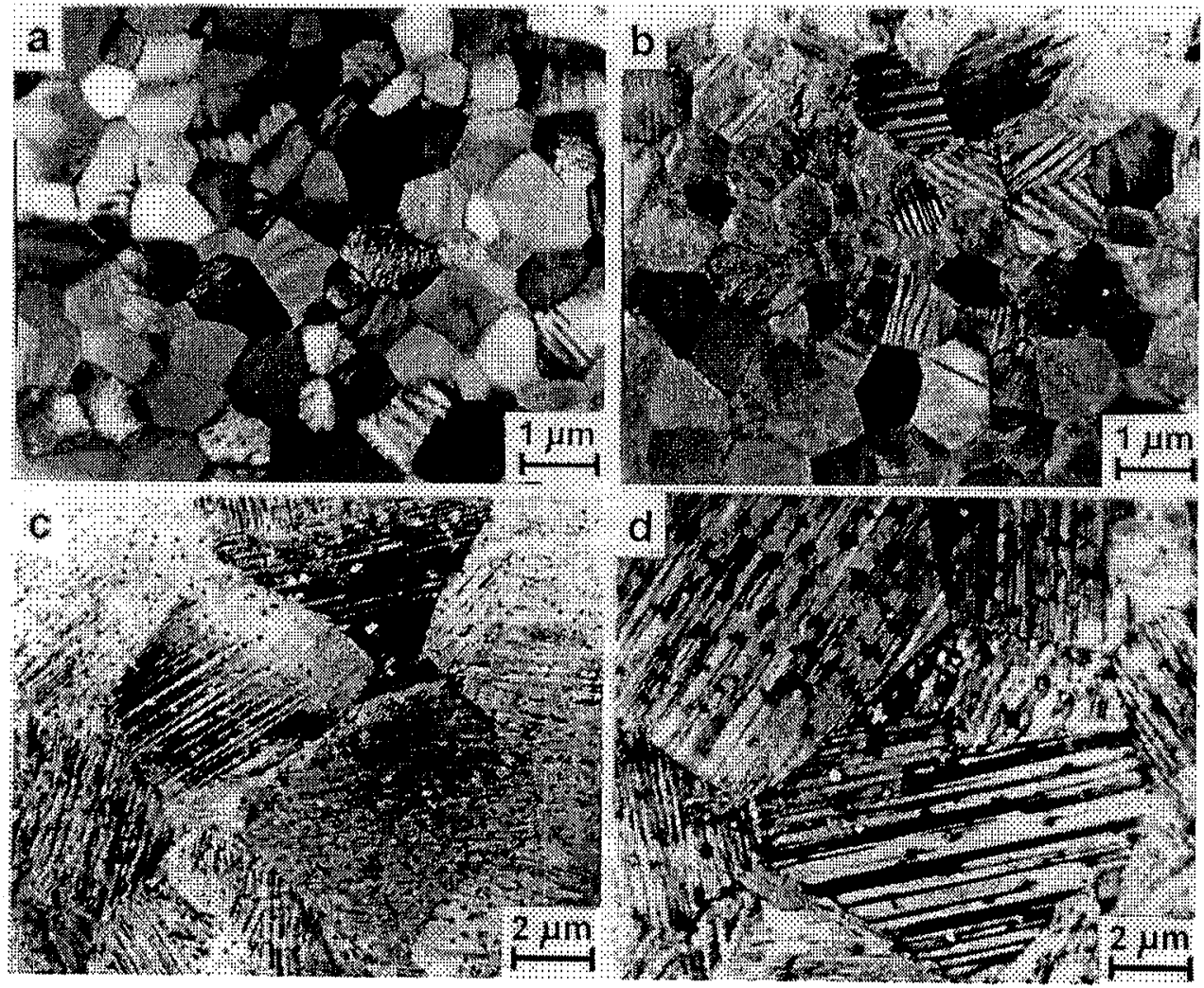

Fig. 15. Transmission electron micrographs of the ribbons from the alloy 94 melt spun at various wheel speeds: $6.5 \mathrm{~m} / \mathrm{s}(\mathrm{a}), 16.6 \mathrm{~m} / \mathrm{s} \mathrm{(b),} 31 \mathrm{~m} / \mathrm{s} \mathrm{(c),} \mathrm{and} 43 \mathrm{~m} / \mathrm{s}(\mathrm{d})$.

uration of titanium is rather weak comparing with the grain size effect. However, since there is a scatter of data one cannot exclude influence of other factors, like ordering as suggested for melt spun CANTIM alloys [30] and precipitation [28]. 
In order to clarify the observed changes of transformation temperatures transmission electron microscopy was applied. Figure 15 shows a set of micrographs taken from the alloy 94 cast at various wheel speeds leading to different grain sizes. The ribbons cast with a rate between $6.5-31 \mathrm{~m} / \mathrm{s}$ show a martensitic structure within grains of decreasing size with a wheel speed, with fine $\mathrm{Cu}_{2} \mathrm{AlTi}$ precipitates. The precipitates are placed uniformly within the grains. The ribbon cast at $43 \mathrm{~m} / \mathrm{s}$ shows the $\beta$ grains due to low transformation temperature and of a smaller size when compared to the others. One can distinguish a modulated structure within $\beta$ grains which is most probably originating from the premartensitic phenomena and can be attributed to the surface effects. Contrary to the alloy 94 with a higher manganese content in alloy 95 (Cu $11.8 \% \mathrm{Al} 5.0 \% \mathrm{Ni} 2.0 \mathrm{Mn}$. $0.4 \% \mathrm{Ti}$ ) cast at the same rate one can observe small precipitates distributed homogeneously within martensitic plates. The presence of precipitates in ribbons cast at all cooling rates may be the reason for the larger shift of transformation temperatures in this alloy due to coherency stresses involved. The ordered $\mathrm{DO}_{3}$ domains in melt spun ribbons are of a similar or even larger size than in the bulk alloys, similarly as observed in Ref. [20]. In the present case it may be caused by a slow cooling from the elevated temperature range possessed by the ribbon leaving the wheel. Another reason can be the chemical composition of the solid solution which may vary with a size and density of precipitates.

\section{Acknowledgments}

The partial support by the INCO-COPERNICUS grant No. IC15-CT96-0704 is gratefully acknowledged.

\section{References}

[1] C.M. Wayman, Scr. Metall. Mater. 5, 489 (1971).

[2] G.V. Kurdyumov, L.G. Khandros, Dokl. Akad. Nauk SSSR 66, 211 (1949).

[3] H. Pops, T.B. Massalski, Trans. AIME 209, 1662 (1964).

[4] J. Van Humbeeck, L. Delaey, in: The Martensitic Transformation in Science and Technology, Eds. E. Hornbogen, N. Jost, DGM Verlag, Oberursel 1989, p. 15.

[5] C. Lopez del Castillo, B.G. Mellor, M.L. Blazquez, C. Gomez, Scr. Metall. Mater. 21, 1711 (1987).

[6] N.F. Kennon, D.P. Dunne, L.N. Middleton, Metall. Trans. A 13, 551 (1982).

[7] M. Chandrasekaran, E. Cesari, J. Wolska, I. Hurtado, R. Stalmans, J. Dutkiewicz, J. Phys. Colloq. C 2, 143 (1995).

[8] R. Rapacioli, M. Chandrasekaran, in: Proc. Conf. ICOMAT 79, M.I.T. Press, Cambridge (Mass.) 1979, p. 596.

[9] A. Abu Arab, M. Chandrasekaran, M. Ahlers, Scr. Metall. Mater. 18, 709 (1984).

[10] K. Otsuka, K. Shimizu, Int. Metals Rev. 31, 93 (1986).

[11] C. Rodriguez, L.C. Brown, in: Shape Memory Effects in Alloys, Ed. J. Perkins, Plenum Press, New York 1975, p. 29.

[12] T. Saburi, Y. Inada, S. Nenno, N. Hori, J. Phys. C4 43, 633 (1982).

[13] H. Kato, J. Dutkiewicz, S. Miura Acta Metall. Mater. 42, 1359 (1994). 
[14] V.V. Martynov, K. Enami, A.V. Tkachenko, L.G. Khandros, Dokl. Akad. Nauk $S S S R$ 258, 608 (1981).

[15] J. Dutkiewicz, V.V. Martynov, U. Messerschmidt, J. Mater. Sci. 24, 3904 (1989).

[16] G. Scarsbrook, W.M. Stobbs, Acta Metall. Mater. 35, 47 (1987).

[17] S. Eucken, E. Hornbogen, in: Proc. ICOMAT-86, Japan Institute of Metals, Sendai 1987, p. 780.

[18] S. Matsuoka, M. Hasebe, R. Oshima, F.E. Fujita, Jpn. J. Appl. Phys. 2 Lett. 22, L-528 (1983).

[19] S. Eucken, E. Hornbogen, in: Proc. ICSMA 7, Pergamon Press, Oxford 1985, p. 1615.

[20] J. Dutkiewicz, J. Morgiel, T. Czeppe, E. Cesari, ESOMAT 97, J. Phys. IV, Colloq. $C$ 5, 167 (1997).

[21] J. Dutkiewicz, M. Chandrasekaran, E. Cesari, Scr. Metall. Mater. 29, 19 (1993).

[22] W. Stobbs, J. Microsc. 129, 307 (1983).

[23] P. Rodriguez, PhD. Thesis, INSA, Lyon 1989.

[24] H. Xu, S. Tan, Scr. Metall. Mater. 33, 749 (1995).

[25] R. Stalmans, J. Van Humbeeck, L. Delaey, Acta Metall. Mater. 40, 501, 2921 (1992).

[26] J. Dutkiewicz, J. Mater. Sci 29, 6249 (1994).

[27] F.C. Lovey, P.L. Rodriguez, J. Malarria, M. Sade, V. Torra, J. Phys. IV Colloq. C2 5, 287 (1995).

[28] J. Dutkiewicz, J. Pons, E. Cesari, Mater. Sci. Eng. A 158, 119 (1992).

[29] C. Segui, E. Cesari, J. Van Humbeeck, Mater. Trans. JIM 32, 898 (1991).

[30] J.H. Zhu, D.P. Dunne, G.W. Dillamore, N.F. Kennon, in: Proc. ICOMAT-92, Monterey, Eds. C.M. Wayman, J. Perkins, Institute for Advanced Studies, Monterey 1992, p. 1083. 